\title{
El valor del agua en la agricultura
}

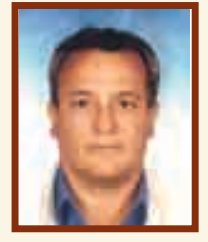

Ing. Hernán Avilés L.

La creciente necesidad de lograr el equilibrio hidrológico que asegure el abasto suficiente de agua a la población se logrará armonizando la disponibilidad natural con las extracciones del recurso mediante el uso eficiente del agua.

La obtención del agua se da través de fuentes (2) tales como ríos, arroyos y acuíferos del subsuelo. Estos acuíferos se recargan de forma natural en época de lluvias.

Sin embargo, la época de lluvias tiene una duración promedio de cuatro meses, lo que propicia una escasa captación. Sumado a esto, del total de agua captada por las
Ios diferentes sectores de la población: el agrícola, el industrial, el doméstico y de servicios y para la generación de energía eléctrica, entre otros.

lluvias, aproximadamente el 70\% se evapora.

La desproporción que existe entre la cantidad de agua que se capta por escurrimiento y las extensiones territoriales que comprenden asociadas a la corta temporada de lluvias, hacen que la disponibilidad de agua sea cada vez menor.

Bajo este panorama se enfrentan actualmente graves problemas de disponibilidad, desperdicio y contaminación del agua.

Parte de esta problemática, se enfrenta con la construcción de la Infraestructura Hidráulica, la misma que permite satisfacer de agua a

\section{La escasez del agua}

Las fuentes, los manantiales, las cuencas o cañadas se enfrentan a una acelerada extinción, los cambios existentes (1) tanto en el clima como en el suelo, provocan inundaciones, sequías y desertización. Pero es la acción humana el elemento más drástico: ejerce una deforestación delirante, ignora los conocimientos tradicionales, sobre todo de las comunidades indígenas locales, retira el agua de los ríos de diferentes maneras, entre otras con obras de ingeniería, represas y desvíos.

Y es que ante una situación de escasez del agua, la amenaza se

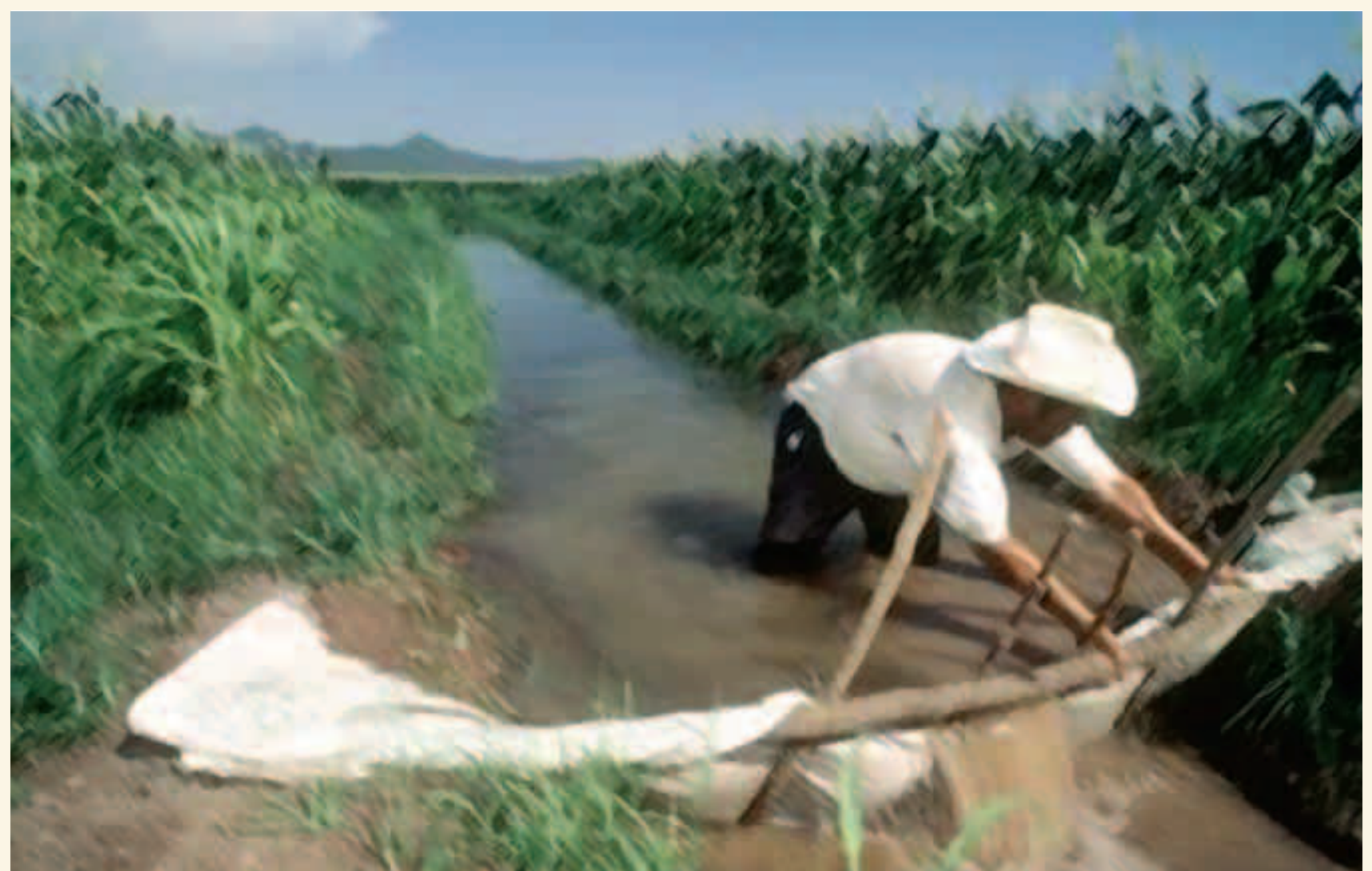


cierne sobre tres aspectos fundamentales del bienestar humano: la producción de alimentos, la salud y la estabilidad política y social. Esto se complica aún más si el recurso disponible se encuentra compartido, sin considerar el aspecto ecológico. Es por esto que, la gestión del recurso deberá tender a evitar situaciones conflictivas debidas a escasez, sobreexplotación y contaminación, mediante medidas preventivas que procuren un uso racional y de conservación.

El agua es un recurso imprescindible, pero escaso para la vida. Menos del $1 \%$ del agua del planeta es dulce y accesible para el hombre, aunque este porcentaje varía considerablemente según el lugar, el clima o la época del año.

\section{EI sector agrícola, mayor consumidor del agua}

El sector agrícola es el mayor consumidor de agua con el 65\%, no sólo porque la superficie irrigada en el mundo ha tenido que quintuplicarse, sino porque no se cuenta con un (3) sistema de rie- go eficiente, razón principal que provoca que las pérdidas de este elemento se tornen monumentales. Le siguen el sector industrial que requiere del $25 \%$ del mismo y a continuación el consumo doméstico, comercial y de otros servicios urbanos municipales que requieren del 10\%. Para el año 2015 el uso industrial alcanzará el $34 \%$, a costa de reducir al 58\% los volúmenes destinados para riego, y al $8 \%$ los de otros usos. El consumo total de agua se ha triplicado desde 1950 sobrepasando los $4.300 \mathrm{~km}^{3} /$ año, cifra que equivale al 30\% de la dotación renovable del mundo que se puede considerar como estable.

Ante estas circunstancias muchas regiones del mundo han alcanzado el límite de aprovechamiento del agua, lo que los ha llevado a sobreexplotar los recursos hidráulicos superficiales y subterráneos, creando un fuerte impacto en el ambiente.

Las razones son diversas, pero podríamos citar dos de estas: La mayor parte de la población mundial vive en cuencas compartidas, lo que implica una mayor

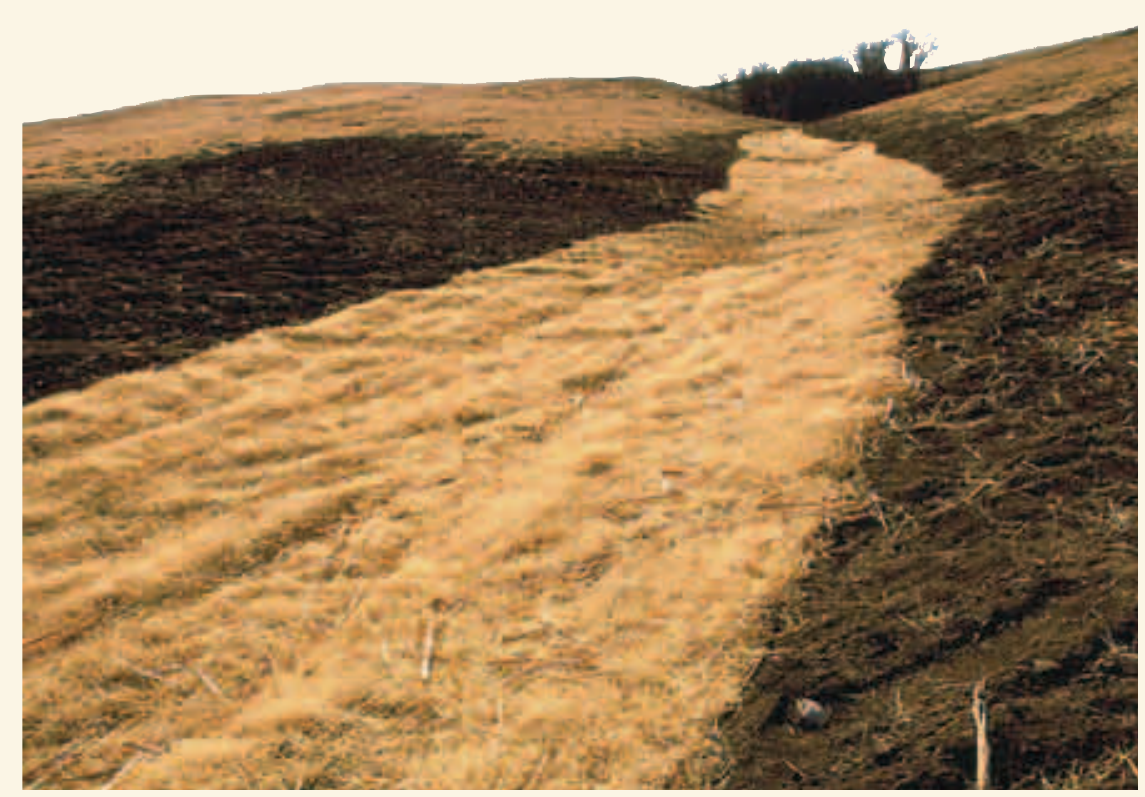

competencia debida a los usos, 50 países de los cuatro continentes asientan más de tres cuartas partes del total de su población en las cuencas internacionales; Io que hace que el $47 \%$ de la población se encuentre en cuencas compartidas internacionales; 214 cuencas son multinacionales, incluyendo 57 en África, 58 en América, 48 en Europa y 51 en Asia.

La situación jurídica sobre el uso y conservación del recurso que se comparte casi siempre en los PED tradicionalmente es ambigua, ya que prácticamente enfrentan una ausencia de reglamentación, sin embargo de que los países desarrollados han generado regulaciones y metodologías para una mejor gestión del recurso, no porque sean más precavidos, sino porque los problemas de contaminación de las aguas los comenzaron a enfrentar desde la época de los años 60 y 70, así tenemos que han logrado desarrollar alta tecnología y diversidad de metodologías para su conservación. El agotamiento del agua subterránea es la amenaza oculta para la seguridad de los alimentos.

La oferta de alimentos (4) de muchos países en desarrollo depende del agua subterránea que se utiliza para irrigación. Si ese recurso no se administra de forma más sostenible, algunas de las zonas más pobladas del mundo pueden enfrentarse a una crisis profunda en el futuro.

Los usos del agua se determinan de acuerdo a la ubicación geográfica del lugar, la economía que tiene, las actividades que realizan los miembros de la comunidad y el contexto cultural en el que se combinan cada uno de los aspectos anteriores. 


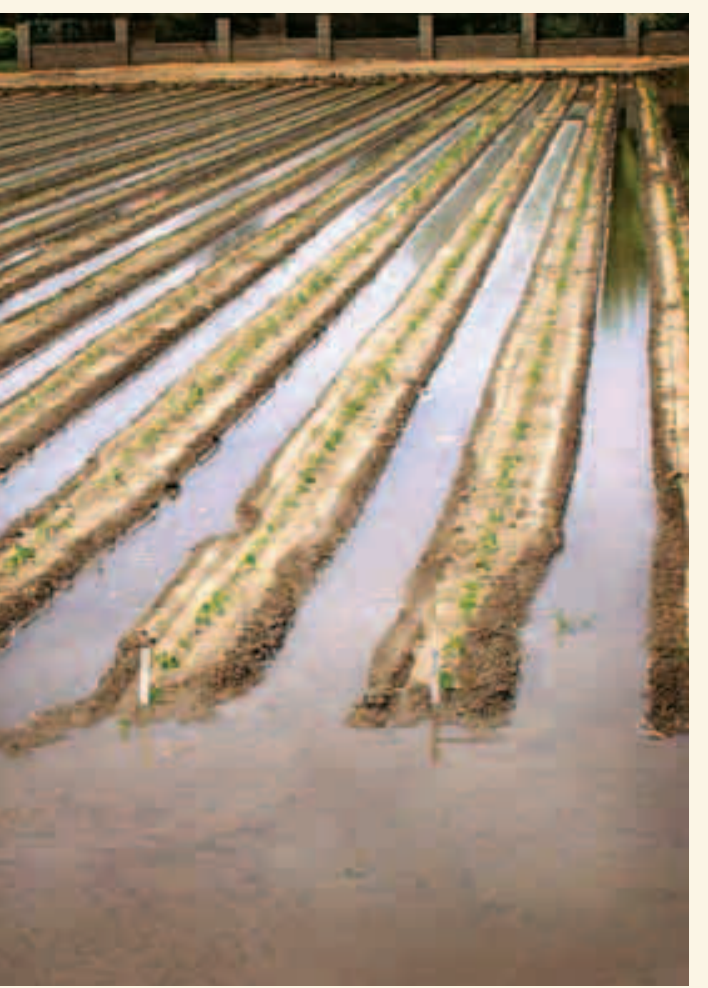

Cada vez es más frecuente ver cómo algunas acciones que realizamos en nuestra comunidad deterioran no sólo la calidad del agua, sino que también nos acercan más a la racionalización severa de este recurso para poder cubrir las necesidades de todos los pobladores. Esta situación nos llevará en pocos años a una escasez de agua que pondría en riesgo el desarrollo social de todos.

Si bien es importante que cada persona valore el uso del agua para sus actividades básicas, es necesaria la organización comunitaria para el manejo eficiente del agua que nos permita preservarla a futuro.

\section{La función ecológica}

Para la ecología, el agua (1) tiene un doble valor: por una parte es un elemento del ecosistema y es consecuentemente un activo social, por otra es generador de ecosistemas.
Son cuestiones muy importantes a considerar, cuando se trata de llevar a cabo aprovechamientos de agua, la conservación de las especies y de los ecosistemas afectados, no podemos olvidar la función que realiza el agua cuando fluye, de modo variable, desde las cabeceras de los ríos hasta el mar, puesto que moviliza y distribuye elementos químicos tan importantes para la vida como el fósforo (P) o el anhídrido carbónico $\left(\mathrm{CO}_{2}\right)$.

La función ecológica del agua en sus dos vertientes fundamentales:

a) mantenimiento de los ecosistemas que le son propios.

b) vehículo_de transporte de nutrientes, sedimentos y vida, es un bien común cuyo respeto debe conciliarse con el desarrollo sostenible de las actividades humanas sobre la tierra.

Es imprescindible revisar los criterios de asignación del agua, especialmente en lo que respecta a las actividades económicas. La incidencia negativa que los nuevos criterios pudieran tener sobre algunos regadíos (hay distintas agriculturas y diferentes agricultores), debe ser corregida considerando la función social que es inherente a la mayor parte de esos regadíos. La subvención de los costes del agua es contraproducente con la asignación eficaz del propio recurso.

La mayor parte del agua dulce, aproximadamente el $70 \%$ del líquido disponible mundialmente, se utiliza en la agricultura. Sin embargo, la mayoría de los sistemas de irrigación son ineficientes: pierden alrededor del 60\% del agua por la evaporación o reflujo a los ríos y mantos acuíferos. La irrigación ineficiente desperdicia el agua y también provoca riesgos ambientales y de salud, tales co- mo la pérdida de tierra agrícola productiva debido a la saturación.

Aunque el $70 \%$ de la superficie del mundo está cubierta por agua, solamente el 2,5\% del agua disponible es dulce; mientras que el restante $97,5 \%$ es agua salada. Casi el $70 \%$ del agua dulce está congelada en los glaciares, y la mayor parte del resto se presenta como humedad en el suelo, o yace en profundas capas acuíferas subterráneas inaccesibles.

Menos del $1 \%$ de los recursos de agua dulce del mundo están disponibles para el consumo, un $17 \%$ más de agua para cultivar alimentos para las crecientes poblaciones de los países en desarrollo, y el consumo total del agua aumentará en un 40\%. La tercera parte de los países en regiones con gran demanda de agua podrían enfrentar escasez severa de agua en este siglo, y para el 2025, dos tercios de la población mundial probablemente vivan en países con escasez moderada o severa.

La agricultura por irrigación es responsable del consumo de aproximadamente el $70 \%$ del agua, y hasta del 90\% en las regiones tropicales áridas. Los consumos de agua para la irrigación han aumentado más de un 60\% desde 1960 .

En agricultura es imprescindible mejorar los sistemas de riego. Las pérdidas de agua dulce en la red de distribución son escandalosas: $25-50 \%$ en urbanas y $40-60 \%$ en agrícolas.

\section{La contaminación del agua}

La contaminación del agua (1) por tuberías de desechos debe ser controlada de alguna manera. 


\section{La Granja I 31}

El déficit local y regional de agua es debido, sobre todo, al aumento de las necesidades surgidas del desarrollo económico y de la explosión demográfica. El hombre ha utilizado el agua para fines cada vez más numerosos, y su dependencia de ese elemento no ha hecho más que crecer.

El recurso agua es cada vez más apreciado, tanto para uso doméstico industrial o agrícola. Su escasez, sobre todo en las zonas áridas y semiáridas, la sitúan como prioridad vital para el desarrollo de las poblaciones: "si no hay agua, no hay vida". Muchos son los programas emprendidos para el uso racional del vital líquido; sin embargo, gran parte de ellos adolecen de objetividad, ya sea por su difícil aplicación o por el elevado costo que representan; es más, se ataca el problema desde puntos de vista sofisticados /se piensa que el modelo más complicado es el mejor); sin embargo, existen oportunidades valiosas que están a nuestro alcance, que solo requieren ser visualizadas, un tratamiento técnico simple y "conciencia de todos".

Mucho se habla de las plantas tratadoras para reutilización del agua en ciertas actividades donde no se requiere la calidad de potable (claro, dado el acondicionamiento de las aguas degradadas). Adicionalmente, la contaminación causada por los efluentes domésticos e industriales, la deforestación y las prácticas del uso del suelo, están reduciendo notablemente la disponibilidad de agua utilizable. En la actualidad, una cuarta parte de la población mundial, es decir, mil quinientos millones de personas, que principalmente habitan en los PED (Países en Desarrollo) sufren escasez severa de agua limpia, Io que ocasiona que en el mundo haya más de diez millones de muertes al año producto de enfermedades hídricas.

Además hay que subrayar que no cabe relacionar la escasez del agua con las entradas por precipitación, pensando que se pueden canalizar en su totalidad hacia los usos: éstas se han de dividir en tres partes, una se evapora en la atmósfera, otra se fija en el suelo, en la vegetación y los organismos que componen la biosfera y otra es la que va por los cauces y lagos superficiales y subterráneos hacia el mar. Y solo de esta última parte cabe derivar agua hacia los usos antrópicos, pero sin agotar cauces o acuíferos, para evitar los daños sociales y ecológicos derivados de su sobreexplotación.

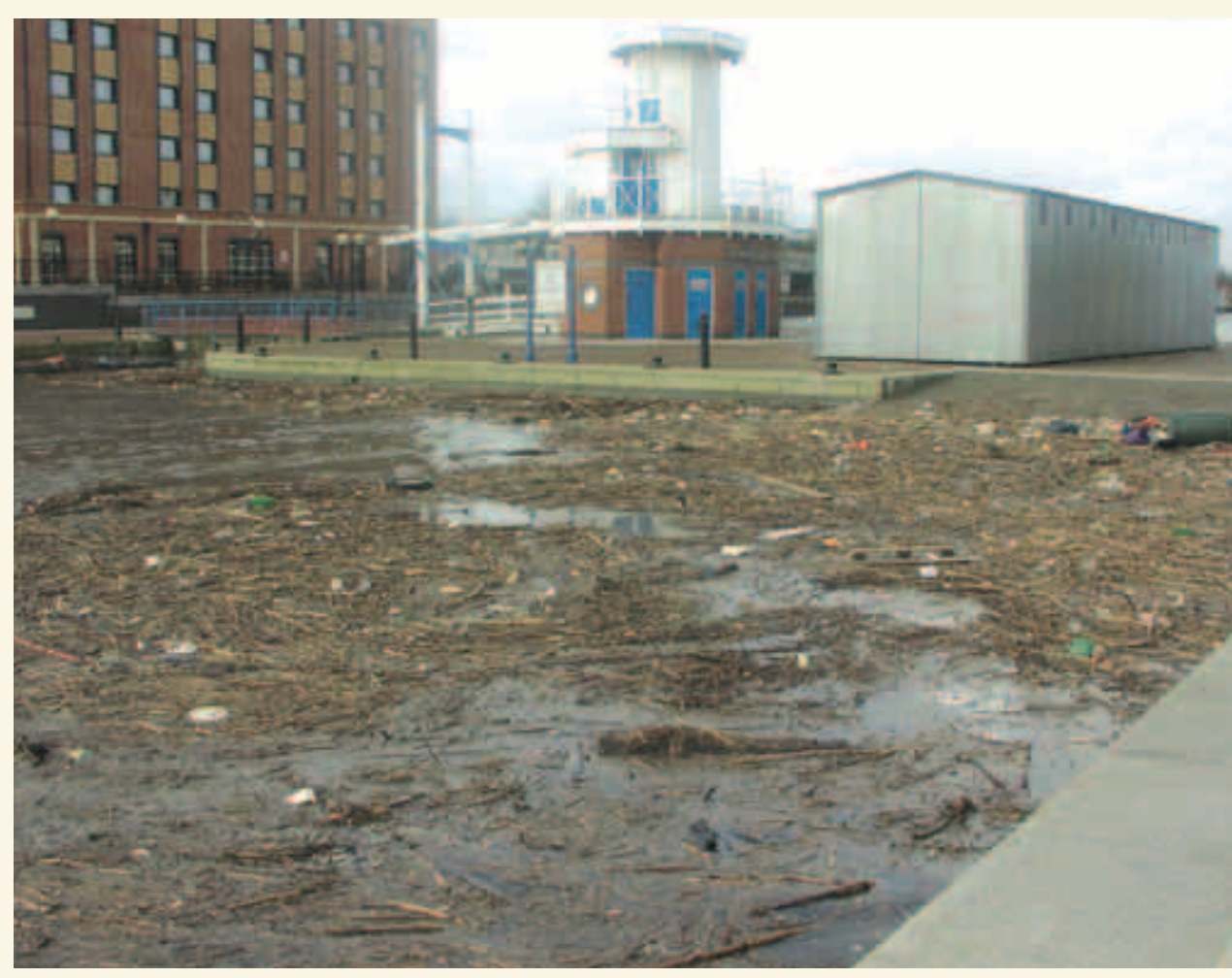

\section{Bibliografia}

1. Perspectivas del medio ambiente mundial 2000 PNUMA Ed. Mundi-Prensa.

2. ALFARO J.F. Adaptación de 2 sistemas de irrigación para suelos arenosos. Proine. Brasilia. 1988. 85 pp.

3. ISRAELSEN, O.W. Principios y prácticas de riego. Ed. Reverte. Barcelona.

4. Alberto Lozada Villasante. Agricultura y desarrollo rural U.P. MADRID 2002. 